\title{
Strengthening interlinked marketing exchange systems to improve water and sanitation in informal settlements of Kigali, Rwanda
}

Inadequate water, sanitation and hygiene (WASH) is a significant health burden in Rwanda. Although current approaches for improving water and sanitation provision to enhance health outcomes are often narrowly associated with monetary exchange, analysis of two informal settlements in Kigali (Gitega and Kimisagara) shows that households attempt to meet their water and sanitation needs through four interlinked exchange systems (market-based, commandbased, culturally determined and non-market-based exchange systems). By focusing on existing social relations and exchange systems, sanitation practitioners may be able to foster and strengthen these interlinked water and sanitation marketing exchange systems embedding in the local context and local capabilities, and as a consequence improve the lives of the low-income communities of informal settlements.

Keywords: marketing exchanges; water; sanitation; health; Rwanda

\section{Introduction}

Diarrhoea is the fourth leading cause of death worldwide and, despite a downward trend in deaths attributed to diarrhoea, still claimed 1.4 million lives in 2010 (Lozano et al. 2012). Inadequate water, sanitation and hygiene (WASH) is responsible for a major proportion of these deaths (Pfadenhauer and Rehfuess 2015). The World Health Organization (WHO) and United Nations International Children's Emergency Fund (UNICEF) Joint Monitoring Programme (JMP) estimates that $9 \%$ a safe water source and $32 \%$ of the world's population do not use a safe sanitation facility (WHO / UNICEF 2015).

In Rwanda, the picture on improving household access to basic infrastructure and services is variable. Based on the National Strategy for Transformation (NST_1) as adopted in October 2017, households with access to an improved drinking-water source (excluding time and distance criteria) were estimated at $85 \%$ in 2017; approximately 
$84 \%$ of households use basic improved sanitation services (if some criteria such as sanitation facilities not being shared between households are excluded) (GoR 2017). Considering the Sustainable Development Goals (SDGs), especially Goal\#6 indicators and according to the 2017 JMP Report, the percentage of households using basic ${ }^{1}$ drinking water services was estimated at $57 \%$ while $62 \%$ of households use basic ${ }^{2}$ sanitation services (GoR 2018b).

However, informal settlements, which are common in most Sub-Saharan African cities, face unique challenges with. In sub-Saharan Africa approximately $62 \%$ of the urban population live in informal settlements (Shah 2016, Dinye and Acheampong 2013). Informal settlements present a real challenge for achieving sustainable urban development and improved health and quality of life for urban residents. Part of this challenge includes dealing with the lack of basic improved-sanitation facilities, and the consequent unhygienic disposal of human waste through means such as open defecation.

Rwanda has been experiencing a very high rate of population and urban growth. Urban growth is largely concentrated in the City of Kigali, which today accommodates about half of Rwanda's urban population (Tsinda 2018, GoR 2018a). This has led to the proliferation of informal settlements, resulting in overcrowding, dilapidated housing conditions and environmental degradation. In Kigali, more than $60 \%$ of the urban population live in these settlements (GoR 2018c, 2018a) .

Provision of basic improved-sanitation facilities and services in urban informal settlements in Kigali, as in other cities of low-income countries, however, is complex

${ }^{1}$ According to SDGs, households using basic drinking water services are defined as ones using drinking water from improved water source where the collection time is not more than 30 minutes for a roundtrip including queuing.

2 According to SDGs, households using basic sanitation services are defined as those using improved sa+nitation facility which is not shared with other households. 
due to issues such as the allocation of responsibilities between landlords and tenants being ill-defined, insecure land tenure discouraging investment in sanitation, and differences in residents' social backgrounds reducing social cohesion (Lüthi 2010, Simiyu 2017).

Previous research by the authors showed a disparity between supply and demand in the sanitation markets of informal settlements of East African Cities, including Kigali (Tsinda et al. 2015, Tsinda and Abbott 2017, Okurut et al. 2015). However, in lowincome countries water and sanitation markets are multifaceted and can only be understood via analysis which goes beyond supply and demand in monetary terms.

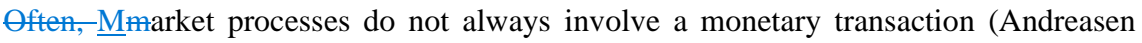
1994) and are not conducted by a conventional buyer and a seller (Barrington et al. 2017). Instead, exchange in the marketing literature can be understood more broadly as a voluntary trade of something of value, with such exchanges including transactions undertaken via social currencies (such as caring for a friend when they are unwell) or via philanthropy (such donating to local charity) (Barrington et al. 2017).

Marketing research identifies a range of exchange partners and their motivations for participating in the market (Laczniak and Murphy 2012, Sridharan et al. 2015). This broader understanding of exchange suggests that water and sanitation markets can involve a multitude of exchange partners who interact via both monetary and nonmonetary transactions to enhance health and wellbeing, through both the water and sanitation products and services exchanged, and an increase in social capital created by the exchange itself (Mohnen et al. 2011, Yip et al. 2007, Poortinga 2016).

This article builds on theories of social exchanges where marketing exchanges are classified into four categories (Sridharan et al 2015, Barrington et al. 2017): (i) market-based, ii) gift economy, gift culture or gift exchange (non-market-based), iii) 
command-based and iv) culturally-embedded. TWe apply this framework, developed by Sridharan et al. and Barrington et al., was applied and adapted to it in the Rwandan context.

In a typical market-based exchange, goods and services are exchanged for primarily monetary value received (Tsinda et al. 2015). A market- based exchange allows a buyer to access goods or services while allowing the seller an opportunity to make an economic profit (Sridharan et al. 2015).

In a gift exchange, products (or services) are not formally traded or sold for money but instead are given without any explicit agreement of future reward (Cheal 2015, Kranton 1996). In the context of the water and sanitation the gift economy (or non-market exchange system) is often criticised because the recipients do not necessarily feel invested or have a full sense of ownership of the resulting water and sanitation supply solution (Marks and Davis 2012).

In a command-based exchange, a government owned authority provides goods and services as a result of a provision obligation set through legislation rather than profit motive (Sridharan et al. 2015). The provision obligation stems from the need to ensure the right to water and sanitation is upheld for the local population. However, command-based exchange systems have been criticised for providing people with a poor range of options, lacking recipients engagement in the planning process and their $\underline{\mathrm{a}}$ lack of responsiveness to changing needs and local conditions (Mitlin 2004). In the context of water and sanitation, examples of command-based exchanges include community boreholes or wells provided by the local government, large-scale water supply infrastructural projects and city-wide sewerage systems (Barrington et al. 2017).

In a culturally_-determined exchange, the provider and recipient engage in an exchange transaction primarily governed by local social practices instead of by 
conventional economics (Belk 2014, Bisung and Elliott 2014, Thapar 1994). The motivations for such exchanges are culturally rooted and based upon reciprocity and the local equitable redistribution of resources (Layton 2007). The result of such an exchange tends to be a collectively beneficial outcome instead of a purely individual gain (Layton 2007, Domegan et al. 2016). For example, in a household in an informal urban settlement may split its water bill with another household, reducing the fixed access costs for both households and thus make getting a water supply connection more affordable, while in a rural area a community-scale water system may be managed by a local committee seeking to ensure that all villagers have access to sufficient water (Sridharan et al. 2015).

It is against this background that this article aims to-appliesy a framework of water and sanitation marketing exchange systems based on the four types of exchange systems outlined above, in the context of the informal settlements of Kigali, Rwanda. The findings contribute to developing new insights into how the four exchange systems can be used to ensure water and sanitation provision is responsive to households' needs and wants as societies move towards universal equitable access.

\section{Method}

\section{Study area}

AnWeThe-applied the exchange systems framework via a case study research approach was applied via a case study research approach to- TheOur case study is__Kigali, the capital city of Rwanda, which has an estimated population of 1 million (World Bank 2017). There are a number of informal settlements around the city, with about $63 \%$ of the population of Kigali City still living in informal settlements (Tsinda et al. 2013). 
Two informal settlements of the City of Kigali, Gitega and Kimisagara, were selected as research sites. The characteristics of these two may be summarised as follows: (i) high density of settlement, (ii) an unhealthy environment, (iii) unauthorised, poor housing, (iv) lack of access to quality transportation, (v) lack of access to quality health care, (vi) poor drainage systems, and (vii) poor sanitation facilities and services.

\section{Data collection and analysis}

In this study,-we used a purposive sampling framework was used to select informants, using the same framework in both settlements. In-depth interviews and focus-group discussions (FGDs) were used to capture the informants' perspective on different marketing exchange systems in water and sanitation. This article draws primarily on key informant interviews with officials from the Ministry of Infrastructure (MININFRA), the Water and Sanitation Corporation (WASAC), the Rwanda Utilities Regulatory Authority (RURA) ${ }^{3}$, officials of the City of Kigali District of Nyarugenge, Kimisagara and Gitega Sectors. TWe also draw on t ten FGDs with owner-occupiers (half female and half male) who were the head of households; two FGDs with community health workers; two FGDs with village leaders; and two FGD with service providers in the settlements, were conducted. The discussions were facilitated by two trained researchers and each group was deliberately limited to six to eight participants in order to facilitate meaningful interaction.

\footnotetext{
${ }^{3}$ It is important to give a brief explanation of the roles and responsibilities of the above three key national institutions: (i) MININFRA is a ministry responsible for the development of policies and regulations regarding sanitation, water, urbanisation (including informal settlements) and housing, (ii) WASAC is a national entity set up to manage the water and sanitation services in Rwanda, (iii) RURA is a government agency with a mission to regulate certain public utilities, including water, sanitation, energy, etc.
} 
Finally, arranged a one-day workshop was arranged to seek the views of stakeholders on preliminary research outcomes and their insights into water- and sanitation-related marketing exchange mechanisms in the two settlements. The workshop was designed to bring together stakeholders and various interest groups, with participants being selected by purposive sampling. The workshop consisted of 15 participants representing residents (including owner-occupiers and renters of both genders), service providers from the settlements, local village leaders (one from each settlement), two district officials, one official from the City of Kigali and officials from WASAC, RURA and MININFRA. The above three qualitative research methods are seen here as complementary rather than alternatives.

\section{Data management and analysis}

All FGDs were conducted in Kinyarwanda (the local language) and were later translated into English. The key informant interviews and workshop were conducted in English with a little explanation in Kinyarwanda. Data from interviews, FGDs and workshop were recorded on audio devices, after which they were transcribed verbatim into Microsoft Word. These transcripts were then read multiple times in order to gain familiarity with the data.

Data analysis followed a thematic content approach. The main themes built on social exchange theories, classified into the four categories of the Framework: (i) marketbased, ii) non-market-based, iii) command-based and iv) culturally embedded.

Before each interview, respondents were advised of the aims of the study and given time to make an informed decision on whether to participate. Ethical approval was given by the University of Rwanda (UR) Research Screening and Ethics Clearance Committee. 


\section{FindingsResults}

The findings show that, in two informal settlements of Kigali, water and sanitation products and services were are supplied by all four types of exchange systems. Examples of these types of water and sanitation exchange system are shown in Figure 1.

Insert Figure1 near here.

However, in practice the four exchange systems are not mutually exclusive and frequently co-exist in complementary ways. As identified by Sridharan et al (2015), these exchange systems can exist as interlinked systems which work together, or as a hybrid system. In the following sections, each exchange system is described (with practical examples), followed by a discussion of the and it is concluded we finish by diseussing a complex system where all four exchange mechanisms work together and complement each other, so that the whole is greater than the parts.

\section{Market-based exchange systems}

'The market', for informal settlement residents in Kigali, refers to the small local hardware shops and informal service providers (e.g. informal emptiers, masons, pit diggers, etc.) serving the neighbourhoods.

Participants in the interviews, FGDs and workshop agreed that the following water and sanitation products and services are provided by the market-based mechanisms. These include: (i) water purchased from the public utility or from other households; (ii) ecosan model or semi-ecosan toilets and ventilated pit latrines (VIP) (or other latrine technologies); (iii) septic tanks; (iv) construction services and materials for upgrading existing sanitation facilities (e.g. from a pit latrine to an ventilated pit latrine, 
or adding a cement floor, door, etc.); (v) soap, (vi) simple hand washing equipment or Kandagira ukarebe ${ }^{4}$.

\section{Command-based exchange systems}

Although water is sold via a market-based transaction to households by individual sellers, the price of the transaction is regulated by RURA, a government regulatory authority. Thus, there is a command-based exchange between the retailer and the

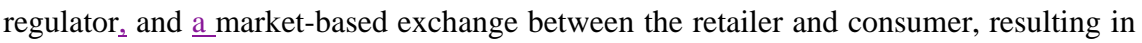
a hybrid command/market exchange for the overall transaction.

RURA is responsible for the day-to-day regulation and supervision of private operator licensing, adherence to minimum service standards, monitoring of agreed performance benchmarks and adherence to agreed tariffs (GoR 2016). Often, RURA cooperates with WASAC, with WASAC playing mainly a supporting role. Furthermore, user associations/committees are involved in the oversight arrangements, representing consumer interests and user rights, as set out in the contractual and regulatory arrangements.

\section{Culturally-determined exchange mechanisms}

Although not widely practiced, it has been observed that some households obtain access to an affordable sanitation facility by two or three households building a shared toilet on land adjacent to one of the houses or the nearest vacant land. This is important because

${ }^{4}$ The Step and Wash (Kandagira ukarabe), is a simple hand washing equipment where a small jar or container with clean water is positioned at the top and connected to a peddle that exerts pressure open the flow of water from the container. 
the majority of owner-occupiers do not have the means to build individual private toilets, as was pointed out by a resident in Kimisagara (Kigali):

"See how many kids I have, I lived here since 1980; this house has three rooms and I use all of them as bedrooms so there is no space available; fortunately I live in harmony with my neighbor and we have constructed a shared toilet in his area and we shared the cost because he is poor like me".

Even if shared toilets are not considered as improved sanitation, it is important to acknowledge that shared toilets are more affordable than individual household toilets and much better than open defecation. That is why some key informants suggest that shared sanitation is inevitable and that emphasis the should be placed on ensuring better standards, better cleaning and a reasonable number of households sharing a single toilet rather than every household having to have its own private toilet.

\section{Non-market-based exchange systems}

A number of stakeholders indicated during the workshop that some water and sanitation products and services are provided by non-market-based exchange mechanisms which are best described by their Rwandan names of imihigo, ubudehe, umuganda, umusanzu, urugerero (See Table 1.).

Insert Table1 near here.

Concerning the above non-market-based exchange mechanisms, one representative of women in a village stated:

“.....In very serious cases, some costs are covered by community contributions in various forms such as umusanzu whereby village leaders mobilise the community to support households who do not have toilets". 
Similarly, some households also confirmed receiving support from their communities, as reported by one resident of Kimisagara:

"We used to get labour and financial support from the family, good friends and good neighbours in the construction of houses and improved latrines".

For the poor households (especially the households in Category 1 of ubudehe $e^{5}$ who do not have toilets) the village leaders organise community members to build sanitation facilities.

Community work or umuganda, which is organised at the umudugudu or village level (lowest level of administration), is followed by ibiganiro (a local community meeting). This meeting is also important for disseminating information to citizens, including information on hygienic practices, with Community Health Workers (CHWs) explaining to people how they can keep healthy by such things as hand washing and keeping their toilets clean. It is generally seen as the responsibility of umudugudu' village leaders to guide and encourage better-off households to support their neighbours who are poor (especially those in Category 1 in the ubudehe classification). About this, two participants in the workshop stated:

“...In my village, our leaders used to sensitize us and raise funds to construct toilets for the very poor and vulnerable households especially older people, widows and orphans of genocide and the practice is now being imitated by our neighbours..."(Female owner-occupier from Gitega, 2016 ).

"At the community and household level, there is a need to try to leverage all local resources and mobilise whatever financial and human resources are available to construct home toilets such as exploiting the local expertise and labour of community members, family members, relatives and friends to

\footnotetext{
${ }^{5}$ See Table 1 for an explanation of the ubudehe socio-economic categories.
} 
provide assistance in the form of labour and materials for toilet construction" (Official from MININFRA, 2016).

Volunteering and voluntary donations are also used to enable the construction of new toilets, the emptying of toilets once they are full, and the construction of Ventilated Pit Latrines (VIP) or other forms of sanitation recommended by the Government. Social support also takes other forms, such as a daughter or son helping an elderly parent to use a latrine, an individual helping his/her neighbour to build a toilet or a resident providing advice to his/her neighbour on how to empty their pit latrine.

\section{Strengthening interlinked marketing exchange systems}

These water and sanitation marketing exchange systems are interlinked. As was often mentioned by the pParticipants in the workshop, the told us about how traditional practices are hybridised with market-based exchanges to ensure that community members have access to water and sanitation. Traditional mechanisms have been adopted into the administrative system to assist with the implementation of national policies and targets within a decentralized structure.

The community support through traditional practices takeøek two forms: firstly two or three residents auld-come together and build a latrine to share, and secondly the community at village level and the diaspora would be organised to contribute finance and labour to build facilities for the very poor and other vulnerable households.

Village leaders would organised collecting voluntary financial contributions and labour is would be provided by community members either as part of umuganda (compulsory community work) or the Vision 2020 Umurenge Programme (a social support programme which boosts the incomes of the poorest members of the community by funding public works). 
These traditional practices and programmes build and enforce the idea of collective action, cooperation and mutual assistance. This demonstrates how the state skilfully draws on the traditional repertoires of local forms of organizations in order to address the developmental issues, including sanitation improvement.

Rather than promoting one-size-fits-all water and sanitation marketing approaches, the approach adopted in Kigali suggests it can be more useful to recognise the resourcefulness with which 'hybrid' exchange modes are developed and applied in the city's informal settlements. The leveraging of social capital to enable the exchange of water and sanitation products and services leads to an improvements in hygienic practices. This has also been reported in other settings (Bakshi et al 2016, Venugopal and Viswanathan 2015).

The mixing of market-based exchanges- together with alternative forms of exchange coupled with an understanding and concern for the well-being of the vulnerable (poor households, widows, people with disabilities, etc..) is consistent with our-recent research findings on the informal settlements of East Africa cities more generally (Tsinda et al. 2017, Tsinda and Abbott 2017).

However, these results here are informative because although water and sanitation market exchanges are triggered by the need to generate survival income, implementation occurs in a humanistic way whereby people support each other through command-based exchange approaches (e.g. local authorities persuading better-off households to support their neighbours) and/or culturally-embedded exchange approaches (e.g. urugerero, enabling young people following the completion of secondary schools to construct houses and sanitation facilities for vulnerable households). 
The research findings also show the complexity of marketing water and sanitation services delivery, because elements are provided by the public sector as a universal right/subsidised but households also remain responsible for purchasing some services on the open market. These-Our findings suggest that in the context of developing water and sanitation marketing approaches the dichotomy of purely profitdriven water service delivery on the one hand or community driver delivery on the other is unlikely to be accurate and therefore not useful in practice. By leveraging and-the varied hybrid exchange practices which exist, WASH practitioners may be able tocan improve the water and sanitation provision to more sustainably meet the needs of local communities.

In the interviews with local leaders 2 it was stressed that social support could not be taken for granted. The participants described a mixed picture of erosion and consolidation of social support under difficult economic conditions. The evidence suggests that where households are linked by monetary exchanges, such as being a member of revolving fund ${ }^{6}$, social support has been strengthened. However, although the very poorest cannot afford to save and therefore cannot benefit directly from membership of revolving funds, the benefits of revolving funds in the context of the case-study settlements of Kigali go beyond monetary exchange and create a collective sense of working together and dealing collectively as a group with daily life issues. This collective approach is useful, as sanitation issues cannot only be solved by an isolated individual - the whole community needs to be involved.

\footnotetext{
${ }^{6}$ This refers to informal financing mechanisms consisting of groups of individuals who make regular contributions to a common fund from which these individuals are inare in turn able to borrow money to pay for sanitation (Chatterley et al. 2013, Hasan 2008, Evans 2009).
} 


\section{Conclusion}

Our researchThe case study of Kigali reveals that- the above identifies a diverse range

of exchange mechanisms used to acquire WASH products and services. These mechanisms include:

1. A market based exchanges, such as the purchase of ecosan toilet from a local provider, the purchase of soap from a shop, and the purchase of water from a privatised (government regulated) water utility.

2. Command-based exchanges which include price regulation imposed by the regulator and on water retailers who are engaging in a market based exchange of the sale of water to consumers. This command based exchange is thus part of a hybrid eommand/market exchange system.

3. Culturally-embedded exchange types, which include practices whereby two or three households share toilets.

4. Non-market-based exchange types such as the use of ubudehe, umuganda, umusanzu, urugerero to support poor households or other vulnerable households without the ability to finance their own access to improved sanitation facilities.

These exchange mechanisms-do not occur in isolation; they are integrated and interlinked, with consumers using multiple forms of water and sanitation marketing mechanisms. While these exchange systems exist as interlinked systems which work together, or as a hybrid system, it is clear that the cultural exchange behaviours are dominant in Kigali and work quite well. Therefore, water and sanitation exchange systems should be designed to generate innovative exchange pathways that are economically, socially, and environmentally sustainable in their local context.

However, even if the-mixed systems exist in other East African cities, the exact practices used in Rwanda would not necessarily work elsewhere because social and 
political economy conditions differ from country to country, and city to city; what works in one country or one city in Eastern Africa will not necessarily work elsewhere. This suggests that further research is required to determine the extent to which practices adopted in Rwanda apply elsewhere.

The way ahead

Formatted: Heading 1, Left

It is widely recognised We all know that savings and loans clubs work-quite well in across low-income countries in Eastern Africa. The Kigali settlements studied here have However, if Rwanda has been relatively-more successful in improving water and sanitation with minimal financial resources from the government and in ways that have proved to work for them, this is becausethem because the principle of Rwanda goes for 'good fit' rather than 'best practice' solutions have been applied (Booth and Cammack 2011, Booth and Golooba-Mutebi 2012). This_implieds a real commitment to 'working with the grain', meaning adopting solutions which are well properly adapted to local contexts and build on existing institutional arrangements that are known to work on the ground and a shift from direct support to facilitating local problem-solving processes (Cammack 2012).

\section{Acknowledgements}

This article was drafted as part of a Post-Doctoral Grants (Post-doc) Scheme through the University of Rwanda, UR-Sweden Programme of Research, Higher Education and Institutional Advancement, which was is funded by the Swedish International 
Development Agency (SIDA). - The authors would like to thank SIDA and the University of Rwanda for the support provided. 


\section{References}

Andreasen Alan R. 1994. Social marketing: Its definition and domain. Journal of public policy \& marketing, 13: 108-114.

Bakshi Rejaul K, Debdulal M, Mehmet A. 2015. Social capital and hygiene practices among the extreme poor in rural Bangladesh. The Journal of Development Studies, 51:12, 1603-1618.

Barrington DJ, Shields SG, Saunders S, Sridharan RT, Bartram J. 2017. Some lessons learned from engaging in WaSH participatory action research in Melanesian informal settlements. In WEDC Knowledge Base. Leeds.

Belk R. 2014. You are what you can access: Sharing and collaborative consumption online. Journal of Business Research, 67: 1595-1600.

Bisaga I, Priti P, Yacob M, Yohannes H. 2018. The potential of performance targets (imihigo) as drivers of energy planning and extending access to off-grid energy in rural Rwanda. Wiley Interdisciplinary Reviews: Energy and Environment: e310.[accessed 2018 December 24]. https://doi.org/10.1002/wene.310.

Bisung E,Susan J. 2014. Toward a social capital based framework for understanding the water-health nexus. Social science \& medicine, 108: 194-200.

Booth D, Cammack D. 2011. Governance for development in Africa. Policy Brief, Africa Power and Politics Programme, UK Department for International Development, London (UK).

Booth D, Golooba-Mutebi F. 2012. Developmental patrimonialism? The case of Rwanda. African Affairs, 111: 379-403.

Cammack, Diana. 2012. Support to local problem-solving: Lessons from peri-urban Malawi. Africa Power and Politics Programme (APPP), Overseas Development Institute, London, UK.

Cheal, David. 2015. The gift economy. Routledge Library Editions: Social and Cultural Anthropology.

Dinye R, Opoku Acheampong E. 2013. Challenges of slum dwellers in Ghana: The case study of Ayigya. Kumasi, Mod. Soc. Sci. J, 2: 228-255.

Domegan C, McHugh P, Devaney M, Duane S, Hogan M, Broome, Layton R, Joyce J, Mazzonetto M, Piwowarczyk J. 2016. Systems-thinking social marketing: conceptual extensions and empirical investigations. Journal of Marketing Management, 32: 1123-1144.

GoR. 2016. National Water Supply Policy. Kigali: Ministry of Infrastructure.

GoR. 2017. National Strategy for Transformation (NST1)-Social Pillar chapter. Kigali: Office of the Prime Minister \& Ministry of Finance and Economic Planning.

GoR. 2018a. Urbanisation and Rural Settlement Sector Strategic Plan (2018-2024). Kigali: Ministry of Infrastructure.

GoR 2018b. Water and Sanitation 2018/2019 Forward Looking Joint Sector Review Report. Kigali: Ministry of Infrastructure.

GoR. 2018c. Water and Sanitation Sector Strategic Plan (2018-2024). Kigali: Ministry of Infrastructure.

Usengumukiza F, Munyandamutsa JP, Nshutiraguma E. 2017. Strengthening democratic governance and accountability in Rwanda:The role of the Rwanda 
Governance Board (RGB). In: Shamsul H M, Shyaka A, Mudacumura G, editors. Democratizing Public Governance in Developing Nations (Routledge).

Kalisa T. 2014. Rural electrification in Rwanda: a measure of willingness to contribute time and money. GATE Working Paper No. 1413. Available at SSRN: https://ssrn.com/abstract=2412519 or http://dx.doi.org/10.2139/ssrn.2412519.

Klingebiel S, Victoria G, Franziska J, Miriam N. 2016. Case Study: Imihigo-A Traditional Rwandan Concept as a RBApp. In: Public Sector Performance and Development Cooperation in Rwanda. Springer International Publishing.

Kranton, RE. 1996. Reciprocal exchange: a self-sustaining system. The American Economic Review, 86 (4): 830-851.

Laczniak G R, Murphy E . 2012. Stakeholder theory and marketing: Moving from a firm-centric to a societal perspective. Journal of Public Policy \& Marketing, 31: 284-292.

Layton R A. 2007. Marketing systems-A core macromarketing concept. Journal of Macromarketing, 27: 227-242.

Lozano R, Mohsen N, Kyle F, Stephen L, Kenji S, Victor A, Jerry A, Timothy A, Rakesh A, Stephanie Y A. 2012. Global and regional mortality from 235 causes of death for 20 age groups in 1990 and 2010: a systematic analysis for the Global Burden of Disease Study 2010. Lancet, 380: 2095-2128.

Lüthi C, Jennifer Mc, Kvarnström E. 2010. Community-based approaches for addressing the urban sanitation challenges. International Journal of Urban Sustainable Development, 1: 49-63.

Marks, J, Jennifer D. 2012. Does user participation lead to sense of ownership for rural water systems? Evidence from Kenya. World Development, 40: 1569-76.

Mitlin D. 2004. Competition, regulation and the urban poor: a case study of water. Leading issues in competition, Regulation and Development, 320-338. Cheltenham: Edward Elgar Publishing.

Mohnen S M, Groenewegen P, Völker B, Henk F. 2011. Neighborhood social capital and individual health. Social science \& medicine, 72: 660-667.

Nzahabwanayo S. 2018. What works in citizenship and values education: attitudes of trainers towards the Itorero training program in post-genocide Rwanda. Rwandan Journal of Education, 4: 71-84.

Okurut K, Nakawunde Kulabako R, Chenoweth J, Charles K. 2015. Assessing demand for improved sustainable sanitation in low-income informal settlements of urban areas: a critical review. International journal of environmental health research, 25: 81-95.

Oyamada E. 2017. Combating corruption in Rwanda: lessons for policy makers. Asian Education and Development Studies, 6: 249-262.

Pfadenhauer L M, Rehfuess E. 2015. Towards effective and socio-culturally appropriate sanitation and hygiene interventions in the Philippines: a mixed method approach. International journal of environmental research and public health, 12: $1902-1927$.

Poortinga W. 2016. Social relations or social capital? Individual and community health effects of bonding social capital. Social science \& medicine, 63: 255-270.

Shah N. 2016. Characterizing slums and slum-dwellers: exploring household-level Indonesian data, University of California, Irvine, Social Science Plaza Irvine.

Simiyu S. 2017. Preference for and characteristics of an appropriate sanitation. technology for the slums of Kisumu, Kenya. International Journal of Urban Sustainable Development, 9: 300-312. 
Sridharan S, Barrington J, Saunders SG. 2015. Water exchange systems.In: Routledge Handbook of Water and Health (Routledge London and New York).

Sundberg M. 2016. Rwanda and Rwandans in the Post-Genocide Political Imaginary. In: Training for Model Citizenship (Springer).

Thapar R. 1994. Cultural transaction and early India: tradition and patronage (Oxford University Press).

Tsinda A. 2018. Affordable Housing in Kigali: Issues and Recommendations. In. Kigali: Institute of Policy Analysis and Research (IPAR-Rwanda).

Tsinda A, Abbott P. 2017. Between the Market and the State: Financing and Servicing Self-Sustaining Sanitation Chains in Informal Settlements in East African Cities.Working Paper 1, Centre for Global Development, University of Aberdeen. Available at SSRN: https://ssrn.com/abstract=2951915 or http://dx.doi.org/10.2139/ssrn.2951915.

Tsinda A, Abbott P, Chenoweth J. 2015. Sanitation markets in urban informal settlements of East Africa. Habitat International, 49: 21-29.

Tsinda A, Abbott P, Chenoweth J, Pedley S, Kwizera M. 2017. Improving sanitation in informal settlements of East African cities: hybrid of market and state-led approaches. International Journal of Water Resources Development: 1-16.

Tsinda A, Abbott P, Pedley S, Charles K, Adogo J, Okurut K, Chenoweth J. 2013. Challenges to achieving sustainable sanitation in informal settlements of Kigali, Rwanda. International journal of environmental research and public health, 10 : 6939-6954.

Usengumukiza F. 2015. Governance for development: the case of Rwanda.In. Kigali: Rwanda Governance Board.

Uwimbabazi P. 2012. An analysis of umuganda: the policy and practice of community work in Rwanda [dissertation]. Pietermaritzburg: University of KwaZulu-Natal, South Africa.

Venugopal S, Madhubalan V. 2015. Developing customer solutions for subsistence marketplaces in emerging economies: a bottom-up 3C (customer, community, and context) approach. Customer Needs and Solutions, 2: 325-336.

WHO / UNICEF. 2015. Progress on DrinkingWater and Sanitation: 2015 Update. In. Geneva: World Health Organisation/ United Nations Children's Fund.

World Bank. 2017. Note1: Urbanization and the Evolution of Rwanda's Urban Landscape. In. Washington World Bank.

Yip, W, Subramanian A DMitchell D, Dominic TS , Jian Wang L, Ichiro K. 2007. Does social capital enhance health and well-being? Evidence from rural China. Social science \& medicine, 64: 35-49. 


\section{Annexes}

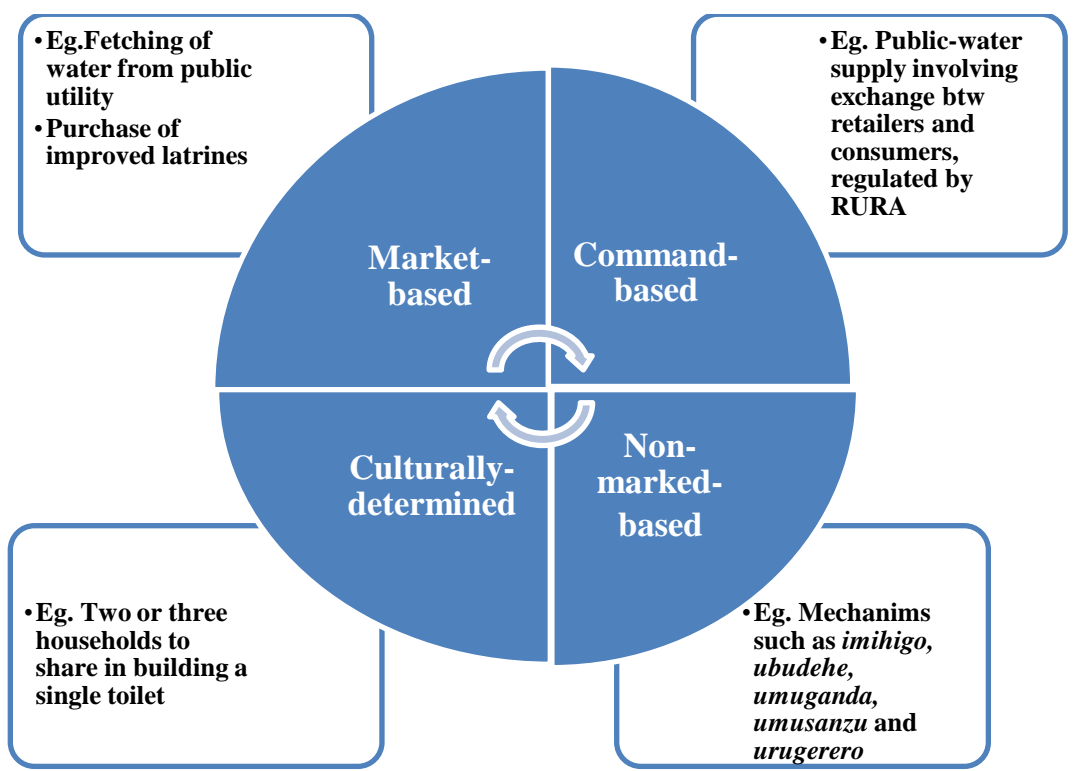

Figure 1: Examples of water and sanitation exchange systems in informal settlements of

Kigali, Rwanda.

Table 1. Non-market and cultural exchange systems used in the water and sanitation area in Kigali, Rwanda.

\begin{tabular}{|l|l|}
\hline$\#$ & Description \\
\hline Imihigo & $\begin{array}{l}\text { A traditional practice where people publicly committed themselves to the } \\
\text { achievement of a given task (e.g. having a hygienic sanitation facility, } \\
\text { access to off-grid energy, etc.) (Oyamada 2017, Klingebiel et al. 2016, } \\
\text { Bisaga et al. 2018). This is done annually in the form of a contract } \\
\text { between H.E, the President of the Republic of Rwanda, the Ministers and } \\
\text { District Mayors and between each household and the village leader. }\end{array}$ \\
\hline
\end{tabular}




\begin{tabular}{|c|c|}
\hline Ubudehe & $\begin{array}{l}\text { A tradition of mutual assistance and local collective action used to } \\
\text { encourage community support for poorer households, including those } \\
\text { without the ability to finance improved sanitation facilities. Under a } \\
\text { participatory poverty classification, all households are allocated a } \\
\text { category based on their socio-economic status. The } 2015 \text { Ubudehe } \\
\text { categorisation covered a total of } 2,358,488 \text { households (10,382,558 } \\
\text { people) across the country and classified them into } 4 \text { categories reflecting } \\
\text { their degree of social and economic need: Category } 1 \text { (16\%): people } \\
\text { without houses, hardly earning, and those affected by food insecurity; } \\
\text { Category } 2 \text { ( } 29.8 \% \text { ): people living on hard labour, masons, people paid } \\
\text { for completed temporally jobs and those capable of renting houses or } \\
\text { have their own houses among others; Category } 3 \text { ( } 53.7 \% \text { ): citizens who } \\
\text { do not need government's support, depend on their incomes - public } \\
\text { servants, farmers who sell excess produce, and private investors with } \\
\text { healthy businesses; and Category } 4 \text { ( } 0.5 \% \text { ): leaders, from directors } \\
\text { generals, mayors of districts, etc. in public institutions up to the President } \\
\text { of the Republic, owners of industries, etc. (GoR } 2017 \text { ). Those in Ubudehe } \\
\text { the provision of sanitation facilities. }\end{array}$ \\
\hline Umuganda & $\begin{array}{l}\text { A traditional cultural practice that predates colonialism which has been } \\
\text { used in various forms to mobilize labour, usually for work on public } \\
\text { projects and support for vulnerable households (e.g. constructing houses } \\
\text { including sanitation, for widows, etc.) (Kalisa } 2014 \text {, Uwimbabazi } 2012 \text {, } \\
\text { Haque, Shyaka and Mudacumura 2017). It is a mandatory community } \\
\text { service held from } 8.00 \text { a.m. to } 11 \text { a.m., carried out on the last Saturday of }\end{array}$ \\
\hline
\end{tabular}




\begin{tabular}{|l|l|}
\hline every month. All able-bodied citizens aged 18 to 65 participate. After the \\
community work, the participants meet to discuss local issues and raise \\
concerns with community leaders. \\
\hline Umusanzu & $\begin{array}{l}\text { A tradition of financial support for the needy and contribution to the } \\
\text { achievement of a common goal, including the community contributions } \\
\text { for the construction of toilets for those who do not have them } \\
\text { community collecting money to help the poorest construct toilets. }\end{array}$ \\
\hline Urugerero & $\begin{array}{l}\text { A traditional custom that has been resurrected whereby young people, } \\
\text { after completing secondary school, have to participate in national service } \\
\text { where they assist in developing the nation with hands-on experience } \\
\text { (Sundberg 2016, Nzahabwanayo 2018), including the construction of } \\
\text { houses and sanitation facilities for vulnerable households such as } \\
\text { households in Category } 1 \text { of } u b u d e h e \text { and widows of genocide against the } \\
\text { Tutsi, etc. This activity is carried out for three to six months each year, }\end{array}$ \\
\hline
\end{tabular}

